\title{
El conocimiento de la religiosidad islámica en la España Moderna: los cinco pilares del islam
}

\section{The knowledge of Islamic religiosity in the Spanish Modern Age: the five pillars of Islam}

\author{
Fernando BrAvo LóPEZ \\ Universidad Autónoma de Madrid \\ fernando.bravo@uam.es
}

Fecha de recepción: 12-11-2018

Fecha de aceptación: 12-03-2019

\begin{abstract}
RESUMEN
El estudio histórico de la religiosidad islámica se ha encontrado tradicionalmente con el problema de la escasez de fuentes. Además, siempre se ha estudiado a partir de las fuentes islámicas, obviando las cristianas. Si es cierto que para la Edad Media las fuentes cristianas no ofrecen demasiada información y están además viciadas por su carácter polémico, también lo es que para la Edad Moderna, con el surgimiento de un tipo de literatura sobre el islam que está alejado de la tradición polémica, disponemos de un buen número de importantes fuentes cristianas que merecen ser tenidas en cuenta en cualquier análisis histórico de la religiosidad islámica. Es el caso especialmente de la Topographía e Historia general de Argel (1612), cuyas descripciones y observaciones resultan de una riqueza sin precedentes.
\end{abstract}

PALABRAS CLAVE: Edad Moderna, cinco pilares del islam, religiosidad, España, Argel.

\section{ABSTRACT}

Traditionally, the historical study of Islamic religiosity has been faced with the problem of the scant amount of sources. Moreover, it has always been approached on the basis of Islamic sources, disregarding the Christian ones. If for the Middle Ages Christian sources do not present much information about the subject and this is tainted by its polemical character, for the Early Modern Age, with the emergence of a new kind of literature about Islam that does not belong to the polemical tradition, we have at our disposal a good number of sources of information. This is particularly the case of the Topographía e Historia general de Argel (1612), with descriptions and observations of an unprecedented quality. It is an evident indication that, from the sixteenth century onwards, there are Christian sources that must be taken into account in any historical analysis of Islamic religiosity.

KEY WORDS: Image of Islam, early modern Spain, five pillars of Islam, religiosity. 


\section{INTRODUCCIÓN}

Uno de los principales problemas a los que se enfrentan los historiadores interesados en reconstruir las formas en las que los musulmanes han vivido su religión en el pasado es la escasez de descripciones detalladas de las prácticas asociadas a la religiosidad islámica. La principal pregunta a la que estos investigadores tratan de dar respuesta es la siguiente: más allá de lo que los manuales de jurisprudencia islámica y los dictámenes de los alfaquíes podían establecer, ¿qué hacían realmente los musulmanes en su vida diaria para cumplir sus obligaciones con Dios ${ }^{1}$ ?

Asumir acríticamente que a lo largo de la historia los musulmanes de todo el mundo han vivido su religiosidad siguiendo estrictamente lo que los alfaquíes recogían en sus tratados y fetuas, resulta, cuando menos, ingenuo. De hecho, tenemos abundantes pruebas de la poco sorprendente — por muy humana — tendencia de los musulmanes a no seguir estrictamente las normas de los juristas, y de la existencia de lo que podría llamarse una religiosidad "popular". "Popular" no por estar basada en diferencias de estatus social, sino por su contraposición a la religiosidad de los intérpretes de la Ley².

Los juristas, efectivamente, veían con disgusto determinadas prácticas religiosas que no consideraban ortodoxas. Así, por ejemplo, es conocida la poco favorable imagen que muchos tenían del culto a los "santones" sufíes. Para estos, tales ritos caían en el pecado de "asociacionismo", que suponía un atentado al principio básico de la unicidad absoluta de Dios $^{3}$. Pero las mayores condenas se las llevaban aquellos ritos que tenían algo de sincrético, pues incorporaban elementos de la religiosidad pagana, judía, cristiana, etcétera. Es el caso, por ejemplo, de la costumbre de celebrar la navidad que tenían algunos musulmanes andalusíes ${ }^{4}$; o de formas de celebración carnavalesca que, como el Nawruz, además de incorporar elementos sincréticos, se situaban entre lo religioso y lo profano ${ }^{5}$; o incluso de la celebración del nacimiento del Profeta, que tampoco gustaba a los juristas, que pretendían mantener un islam libre de innovaciones ${ }^{6}$.

Sin embargo, determinar hasta donde llega, en cada contexto, esa distancia entre el culto codificado de los juristas y el culto real de los creyentes en su vida diaria, resulta difícil. Por lo general, cuando no era para condenarlas por poco "ortodoxas", los autores musulmanes no eran muy dados a describir con detalle sus propias prácticas religiosas, seguramente porque estaban tan normalizadas en sus respectivas sociedades que no vieron necesario recogerlas por escrito.

1 La jurisprudencia islámica distingue dos tipos de obligaciones: aquellas que tiene el creyente con sus semejantes, las muamalat, y aquellas que tiene el creyente con Dios, las ibadat. Éstas son los llamados cinco pilares del islam; véase G. Wiegers, "Ibadat", en R. C. Martin (ed.), Encyclopedia of Islam and the Muslim world, 2 vols., Nueva York, Macmillan Reference USA, Thomson/Gale, 2004, vol. 1, pp. 327-333. Para facilitar la lectura prescindimos de signos diacríticos en la transliteración de términos árabes. El presente artículo ha sido realizado en el marco del proyecto de I+D "Islamofobia: continuidad y cambio en la tradición antimusulmana" (HAR2015-73869-JIN).

2 J. J. Waardenburg, "Official and popular religion in Islam", Social Compass, vol. 25, números 3-4 (1978), pp. 315-341; J. P. Berkey, The formation of islam: religion and society in the Near East, Cambridge, Cambridge University Press, 2003, pp. 248-257.

3 Ibíd.

4 A. García Sanjuán, "La celebración de la navidad en al-Andalus y la convivencia entre cristianos y musulmanes", en J. M. Miura (ed.), Te cuento la navidad, Sevilla, Aconcagua, 2011, pp. 43-49.

5 B. Shoshan, Popular culture in medieval Cairo, Cambridge, Cambridge University Press, 1993, pp. 40-51.

6 J. J. Waardenburg, "Official and popular..."; B. Shoshan, Popular culture..., p. 68; N. J. G. Kaptein, Muhammad's birthday festival: early history in the central Muslim lands and development in the Muslim west until the $10^{\text {th }} / 16^{\text {th }}$ century, Leiden, Nueva York y Colonia, Brill, 1993, pp. 44-67. 
A pesar de la dificultad, algunas descripciones han llegado hasta nosotros, casi todas de época medieval. Se trata de casos especiales, principalmente vinculados al culto de los "santones", cuyo rastro es posible seguir a partir de las biografías que han llegado hasta nosotros ${ }^{7}$. Pero también se trata de eventos que el autor de turno quiso describir porque resultaban inusuales por su magnificencia, por resultar extraordinarios, de tal forma que esas descripciones no nos sirven en ocasiones para conocer cuáles eran las prácticas cotidianas. Es el caso, por ejemplo, de la descripción realizada por Ibn al-Jatib de la celebración del nacimiento de Mahoma en la Granada de Muhammad V ${ }^{8}$. En otras ocasiones se trata de descripciones de prácticas que resultaban habituales en sus respectivas sociedades pero que para el autor resultaban extrañas — porque él mismo era un extraño en esa sociedad-, y por esa razón las recogía por escrito. Es el caso de algunas de las descripciones recogidas por Ibn Yubayr o Ibn Battuta'.

Son, en cualquier caso, escasos los testimonios que pueden resultar de utilidad para realizar un estudio de la religiosidad islámica medieval. Pero existen y se pueden encontrar referencias aisladas en obras de muy diferente naturaleza. Las fuentes en las que el historiador interesado por esta problemática puede buscar esa aislada información son, según Maribel Fierro, múltiples. De hecho, en principio en cualquier texto podría encontrarse información de interés ${ }^{10}$. Y a las fuentes escritas habría que añadir la arqueología, tan útil para, por ejemplo, el conocimiento de las creencias religiosas que se sitúan en la frontera entre lo mágico y lo religioso, y que tienen en los amuletos su testimonio más evidente ${ }^{11}$; 0 para la reconstrucción de los ritos funerarios ${ }^{12}$.

Como se ve, en todo caso se trataría invariablemente de fuentes islámicas, y se centrarían en el período medieval. Para la Edad Moderna, los únicos aspectos de la religiosidad islámica a los que los especialistas han prestado atención han sido el sufismo - con todas sus ramificaciones políticas y sociales vinculadas a las cofradías (turuq, sing. tariqa) y los morabitos - y, en menor medida, la celebración del nacimiento del Profeta y la de ceremonias de circuncisión excepcionales por su magnificencia -y con un sentido más sociopolítico que estrictamente religioso- ${ }^{13}$. El resto de la religiosidad islámica de los siglos XVI a XVIII está en buena medida por estudiar, especialmente aquellos aspectos que

7 F. Rodríguez Mediano, "Religiosidad en al-Andalus: el hombre santo en el islam occidental", Revista de Dialectología y Tradiciones Populares, vol. 54, número 1 (1999), pp. 145-168.

8 Véase M. Cruz Hernández, El islam de al-Andalus: historia y estructura de su realidad social, Madrid, AECI, 1996, pp. 369-370.

9 I. Battuta, A través del islam, traducción, introducción y notas de S. Fanjul y F. Arbós, Madrid, Alianza Ed., 2005, pp. 223 y ss., 563-566, 405-406, 774-775; I. Yubayr, A través del oriente (Rihla), edición y traducción de F. Maíllo, Madrid, Alianza Editorial, 2007, pp. 182-290.

10 M. Fierro, "Prácticas y creencias religiosas en al-Andalus", Al-Qantara, vol. 13, núm. 2 (1992), pp. 463-474.

11 Véase C. Gonzalbes, "Un ensayo para la catalogación de los amuletos de plomo andalusíes", Boletín Arqueológico Medieval, 12 (2005), pp. 7-17.

12 Véase L. Halevi, Muhammad's grave: death rites and the making of Islamic society, Nueva York, Columbia University Press, 2007.

13 Sobre el sufismo, las cofradías sufíes y el culto a los "santones" véase J. Berque, Al-Yousi: problémes de la culture marocaine au XVIlème siècle, París, Moutin \& Co., 1958; H. Touati, Entre Dieu et les hommes: lettrés, saints et sorciers au Maghreb (17e siècle), París, EHESS, 1994; F. Rodríguez Mediano, "Santos arrebatados: algunos ejemplos de maydub en la Salwat al-anfas de Muhammad al-Kattani", Al-Qantara, vol. 13, núm. 1 (1992), pp. 237-256. Sobre la celebración del nacimiento del Profeta véase N. J. G. Kaptein, Muhammad's birthday festival... Sobre la ceremonia de circuncisión otomana véase K. Sahin, "Staging an Empire: an Ottoman circumcision ceremony as cultural performance", American Historical Review, vol. 123, núm. 2 (2018), pp. 463-492. 
resultan más fundamentales, como los cinco pilares del islam, en los que nos centraremos en este trabajo.

Sin duda, para un estudio de ese tipo sería posible identificar fuentes islámicas que, a semejanza de las medievales, recogieran descripciones puntuales de los ritos seguidos por la población musulmana de época moderna. Sin embargo, nuestro propósito en este artículo es adoptar otra perspectiva y plantear la posibilidad de utilizar las fuentes cristianas para reconstruir esas formas de relación de los musulmanes con Dios. Esta es una práctica común -en concreto la utilización de procesos inquisitoriales - en el caso de la reconstrucción histórica de la religiosidad morisca ${ }^{14}$. Pero, en nuestro caso, lo que planteamos es que en tratados de polémica religiosa, en crónicas históricas, relatos de viajes y, sobre todo, en la literatura de cautiverio, es posible encontrar una información que, bien analizada, puede resultar de gran utilidad para el conocimiento de la religiosidad islámica de época moderna.

Sumar a las fuentes islámicas otra serie de fuentes que aportan una perspectiva bien diferente puede ser especialmente enriquecedor en este caso. Las fuentes cristianas conllevan una evidente tendenciosidad. En muchos casos su carácter polémico oscurece todo aquello que tiene que ver con lo islámico, y las acusaciones se mezclan de manera indisoluble con las descripciones que se realizan, de manera que no se sabe muy bien lo contaminadas que están por el espíritu de combate que guía a los autores ${ }^{15}$. Sin embargo, también es posible encontrar descripciones que resultan, al menos aparentemente, neutras. Si lo son realmente o no es lo que trataremos de discutir en este trabajo.

En las siguientes páginas — que no pueden ser más que una primera aproximación al tema- nos centraremos en la información que cabe encontrar acerca del principal aspecto de la religiosidad islámica, los cinco pilares del islam, en la Topographía e Historia general de Argel (1612). La Topographía ${ }^{16}$, como se sabe, es un compendio de cinco obras independientes, una de carácter etnográfico -la propia Topographía, y a esta nos limitaremos en este trabajo_-, otra de carácter histórico —el Epítome de los reyes de Argely tres diálogos: dos sobre la situación de los cautivos cristianos en la ciudad argelina y un tercero que se asemeja a un diálogo de polémica religiosa medieval. En su momento, fue publicada en Valladolid por Diego de Haedo (m. 1613), quien fue abad del monasterio de Nuestra Señora de la Misericordia de Frómista entre 1604 y 1607 . Entre los años 1593 y 1599 fue secretario de su tío, también llamado Diego de Haedo, cuando este era arzobispo de Palermo ${ }^{17}$. Según cuenta el sobrino en la dedicatoria de la obra dirigida a su tío, durante su estancia en Palermo el arzobispo le traspasó unos papeles en borrador en los cuales había recogido toda la información que le transmitieron unos cautivos que habían estado muchos años en Argel. Él les dio su forma definitiva y los llevó a la imprenta.

14 Véase, por ejemplo, M. García-Arenal, Inquisición y moriscos: Ios procesos del Tribunal de Cuenca, Madrid, Siglo XXI, 1987; L. Cardaillac, Moriscos y cristianos: un enfrentamiento polémico, Madrid, FCE, 2016.

15 Sobre la imagen del islam en la España moderna véase M. Á. de Bunes, La imagen de los musulmanes y del norte de África en la España de los siglos XVI y XVII, Madrid, CSIC, 1989.

16 Sobre esta obra la literatura es muy abundante; véase principalmente G. Camamis, Estudios sobre el cautiverio en el Siglo de Oro, Madrid, Gredos, 1977; M. A. Garcés, Cervantes en Argel, Madrid, Gredos, 2005; A. de Sosa, An early modern dialogue with Islam, edición de M. A. Garcés, trad. de D. de Armas, Notre Dame, Ind., University of Notre Dame Press, 2011; M. M. Salah, El doctor Sosa y la Topographía e historia general de Argel, tesis doctoral, Dep. de Filología Española, Universidad Autónoma de Barcelona, Barcelona, 1991. Véase también S. Maliki, "Religiosidad y alteridad: una aproximaicón a la imagen del musulmán en la Topografía e Historia general de Argel de Antonio de Sosa”, 'Ossour al-Jadida, núms. 19-20 (2015), pp. 6682. A pesar de su título, este artículo no realiza ningún análisis de la visión que de la religiosidad islámica se ofrece en la obra.

17 E. Zaragoza, "Abadologio del monasterio de Ntra. Sra. de la Misericordia de Frómista (1437-1835), Publicaciones de la Institución Tello Téllez de Meneses, 71 (2000), pp. 135-158. 
Durante mucho tiempo esta fue la versión de los hechos que se tuvo por buena. Sin embargo, desde finales del siglo XIX se empezó a dudar de ella, y, desde el estudio que George Camamis dedicó a la obra en 1977, muchos autores han defendido la idea de que el autor real de la Topographía fue el clérigo de origen portugués Antonio de Sosa, quien estuvo cautivo en Argel entre los años 1577 y $1581^{18}$. Sin embargo, también se han propuesto otras posibilidades. Daniel Eisenberg, por ejemplo, ha sostenido que, en realidad, el autor de la obra debió de ser un soldado, dada la gran cantidad de información militar que contiene, y que, en tal caso, el candidato ideal sería Miguel de Cervantes ${ }^{19}$.

El principal problema con el que nos encontramos para aceptar la autoría de Sosa es que este murió en $1587^{20}$, mientras que las últimas noticias históricas contenidas en la obra datan de 159621. Esto evidencia que Sosa no pudo ser el autor, al menos no de toda la obra. Quizás lo fuera de una parte - aunque tampoco hay pruebas definitivas de ello ${ }^{22}$-, pero es obvio que otra mano tuvo que trabajar en ella. Camamis supuso que esa otra mano solo era responsable de las últimas páginas del Epítome ${ }^{23}$. Sin embargo, ¿cómo podemos estar seguros de eso? ¿Cómo saber hasta dónde llegó esa otra mano? Si escribió más partes de la obra, si retocó o reescribió más pasajes, si suprimió o añadió información, es algo que, en estos momentos, no se puede saber.

Esto tiene una implicación evidente por lo que a la contextualización histórica de la obra se refiere. Sólo podría contextualizarse en un periodo histórico muy amplio, de más de un cuarto de siglo, entre la captura de Antonio de Sosa en 1577 y la publicación en $1612^{24}$. Ni siquiera podría contextualizarse geográficamente con precisión, puesto que, aunque muchos pasajes llevarían a pensar en un testigo presencial —alguien que escribía en Argel y que presenció lo que veía-, al no saber hasta donde llegó la labor de reescritura posterior, no podríamos asegurar nada al respecto. Así que podría haber sido escrita, total o parcialmente en Argel, pero también total o parcialmente en Palermo o en Frómista. Mientras no se aclare definitivamente la cuestión de la autoría, no será posible contextualizar la obra y llegar a determinar cuestiones tan fundamentales como las relativas a la motivación del autor a la hora de abordar su trabajo, y su intención al decir cada una de las cosas que dijo en ella. Por nuestra parte, hablaremos a lo largo del artículo de Haedo como si fuera el autor

18 G. Camamis, Estudios..., pp. 124-150; M. A. Garcés, “Introduction”, en A. Sosa, An early..., pp. 1-78; E. Sola, "Antonio de Sosa: un clásico inédito amigo de Cervantes (Historia y Literatura)", en Actas del I Coloquio Internacional de la Asociación de Cervantistas, Barcelona, Anthropos, 1990, pp. 409-412; J. Tóth, "Topography of a society: Muslims, dwellers, and customs of Algiers in Antonio de Sosa's Topographia, e Historia general de Argel", en M. D. Birnbaum y M. Sebok (eds.), Practices of coexistence, Budapest, Central European University Press, 2017, pp. 103-142; S. Maliki, "Religiosidad y alteridad..."; M. M. Salah, El doctor Sosa...; J. M. Parreño, "Experiencia y literatura en la obra de Antonio de Sosa", en A. de Sosa, Diálogo de los mártires de Argel, edición de E. Sola y J. M. Parreño, Madrid, Hiperión, 1990, pp. 9-23; E. Sola, "Renacimiento, Contrarreforma y problema morisco en la obra de Antonio de Sosa", en A. de Sosa, Diálogo..., pp. 27-52.

19 D. Eisenberg, "Cervantes, autor de la Topografía e historia general de Argel publicada por Diego de Haedo", Cervantes: Bulletin of the Cervantes Society of America, vol. 16, núm. 1 (1996), pp. 32-53.

20 M. A. Garcés, "Introduction...", pp. 71 y 75.

21 D. de Haedo, Topographía e historia general de Argel, Valladolid, Diego Fernández de Córdova y Oviedo, Imp., 1612, fol. 95v.

22 Camamis y los autores que han aceptado sus conclusiones se basan en algunos indicios que, aunque de peso, no son definitivos. Para poder salir de dudas sería necesario efectuar un análisis estilométrico que comparara los textos de la Topographía entre sí y con aquellos textos de Sosa y los Haedo acerca de los cuales no existe duda sobre su autoría.

23 G. Camamis, Estudios..., p. 145.

24 Aunque la dedicatoria lleva fecha de 25 de diciembre de 1605, la obra pudo ser retocada hasta el momento de su publicación. 
de la obra, dado que se publicó con su nombre, pero no se entienda esto como una toma de posición con respecto a un tema que creemos lejos de estar cerrado.

Sea como fuere, lo cierto es que la obra ha sido considerada por todos los especialistas como una riquísima fuente de información acerca de la historia de la Argel del siglo XVI, y principalmente acerca de la situación de los cautivos cristianos capturados por los corsarios berberiscos - especialmente de Miguel de Cervantes-. Sin embargo, nunca ha sido usada como fuente para el conocimiento de la religiosidad islámica, a pesar, como veremos, de la excepcional riqueza de sus descripciones.

Siendo este nuestro objetivo, consideramos que lo más importante, en cualquier caso, es contextualizar la obra dentro de la tradición intelectual hispanocristiana dedicada al islam. Es situándola en relación con esa tradición como vamos a poder evaluar su valor, su grado de novedad, y su utilidad como fuente cristiana para el conocimiento de la religiosidad islámica. Sin olvidar que, obviamente, no puede ser totalmente aceptada como un acercamiento fiel a la realidad sin su previa comparación con otras fuentes —especialmente las islámicas-, veremos que en esta obra se encuentran descripciones que deben ser tenidas muy en cuenta en cualquier estudio de la religiosidad islámica de época moderna.

Comenzaremos, por tanto, haciendo un breve repaso al conocimiento que de este tema se tuvo en la Europa latina medieval, lo que nos permitirá contextualizar mejor las ideas que acerca de él circularon a partir del siglo XVI, y evidenciar así el cambio crucial que se produjo en ese momento.

\section{LOS FUNDAMENTOS MEDIEVALES}

Si hay algo que caracteriza a la imagen que los autores de la Europa latina medieval transmiten del islam es su fundamento exclusivamente textual. Salvo muy raras excepciones, todo lo que los autores dicen acerca de la religión islámica proviene de lo que han podido recoger de otros textos, y no de la observación directa del culto islámico ${ }^{25}$. Esos textos, hasta el siglo XII, son exclusivamente cristianos. Los autores se basan en lo que las autoridades cristianas anteriores han dicho acerca del islam, y esas autoridades, a su vez, caracterizan la religión islámica a partir de dos fuentes. En primer lugar están la Biblia y los Padres de la Iglesia. En este sentido el islam es percibido como una obra del Maligno, como un castigo divino por los pecados de los cristianos, y se le atribuyen características que habían sido atribuidas tradicionalmente a los enemigos de la Iglesia. En segundo lugar, están algunas fuentes cristianas orientales cuyos autores sí tuvieron conocimiento directo del islam. Sin embargo, esa información es deformada para obtener una imagen más caricaturesca, si cabe, de esta religión, y principalmente de su Profeta. Ni que decir tiene que, si se refieren en algún momento a algún rito vinculado a la religiosidad islámica, se trata de ritos totalmente imaginarios o distorsionados en extremo. Por ejemplo, se transmite la idea de que los musulmanes rinden culto a Mahoma, como si de un dios se tratara ${ }^{26}$.

Sin embargo, a partir del siglo XII esto empieza a cambiar de manera sensible, y este cambio viene provocado porque los polemistas cristianos — siempre con el deseo de refutar la religión islámica- empiezan a prestar atención a lo que los mismos textos islámicos dicen ${ }^{27}$. Gracias a ese conocimiento de las fuentes de la tradición islámica, nos encontramos con la que seguramente es la primera descripción de la mayor parte de los

25 N. Daniel, Islam and the West: the making of an image, Oxford, Oneworld Pub., 1993, p. 254.

26 Sobre este tema me limitaré a citar las obras básicas de referencia: R. W. Southern, Western views of Islam in the Middle Ages, Cambridge, Mass., Harvard University Press, 1962, pp. 1-33; N. Daniel, Islam and the West..., pp. 11-33; J. V. Tolan, Saracens, Nueva York, Columbia University Press, 2002, pp. 71-104.

27 J. V. Tolan, Saracens..., pp. 135-169. 
ritos que conocemos como los cinco pilares del islam, la de Pedro Alfonso. Sin embargo, la descripción de esos ritos no es, ni muy prolija en detalles ni, desde luego, neutral: se hace siempre con el objetivo de mostrar la irracionalidad y falsedad del islam.

La profesión de fe, aunque era muy conocida, no solía mencionarse explícitamente en su totalidad. Sin embargo, una vez reconocido el islam como una religión monoteísta —o más bien como una herejía—, los autores reconocen que los musulmanes no adoran a Mahoma ni a ningún ídolo, sino al mismo dios que los cristianos; mientras que Mahoma es para ellos el último de los profetas. Así, señala Pedro Alfonso, los musulmanes "proclaman en alta voz que creen en un solo Dios que no tiene par ni semejante y que Mahoma es su profeta ${ }^{28 "}$. Y el arzobispo Rodrigo Jiménez de Rada, a mediados del siglo XIII, señala en varias ocasiones que el conflicto entre Mahoma y los miembros de la tribu de Quraish tenía su origen en que estos adoraban ídolos, mientras que él predicaba que debían adorar a un solo Dios ${ }^{29}$.

A la profesión de fe los autores cristianos responderán, obviamente, atacando la segunda de las proposiciones: el carácter profético de Mahoma. Sin embargo, aún así, también habrá quien trate de ridiculizar la fórmula en su totalidad, incluyendo la primera parte, considerándola algo tan evidente que resultaba ridículo sostenerla como fundamento único de la fe; y que, al juntar una proposición verdadera con otra falsa, Mahoma había tratado de engañar más fácilmente a la gente ${ }^{30}$.

Los autores cristianos también sabían que el islam prescribía cinco oraciones diarias a sus fieles ${ }^{31}$. Así, Pedro Alfonso señalaba que Mahoma mandó a sus fieles "orar sólo cinco veces al día32"; y Jiménez de Rada llegó a explicar el origen de la práctica, siguiendo el relato islámico del "Viaje nocturno" de Mahoma ${ }^{33}$. Además, aquellos autores cristianos que convivían con musulmanes tenían muy presente en sus vidas el número de oraciones diarias, porque escuchan al almuédano llamar a la oración: "mandó entonces [Mahoma] que en las torres donde solían tocar las campanas llamase un sarraceno, así como aún hoy se llama a los seguidores de su secta ${ }^{34 "}$. La práctica, con el tiempo, resultaría inaceptable para las autoridades eclesiásticas, que trataron de eliminarla. Así, fue prohibida por el Concilio de Vienne (1311-1312) ${ }^{35}$. Sin embargo, los "sucesivos recordatorios de la prohibición indican que su cumplimiento no fue ni completo ni uniforme ${ }^{36 " .}$.

Que la oración debía realizarse en dirección a La Meca también era sabido. Así, Jiménez de Rada, tras relatar cómo Mahoma ayudó a restaurar el templo de la Kaaba, cuenta que

28 P. Alfonso, Diálogo contra los judíos, traducción de E. Ducay, Zaragoza, IEA, 1996, p. 291.

29 Historia Arabum, II, 50-52; V, 99; VI, 6-7, en R. Jiménez de Rada, Historiae minores. Dialogvs libri vite, edición y estudio de J. Fernández Valverde y J. Antonio Estévez Sola, Turnhout, Brepols, 1999, pp. 87-149.

30 Véase R. Montecroce, Reprobación del Alcorán, Sevilla, por dos alemanes compañeros, 1501, fols. 17r-v.

31 Sobre este tema véase O. de la Cruz Palma, "Las cinco oraciones islámicas diarias (Salawat) en las fuentes latinas medievales", en J. Martínez Gázquez y J. V. Tolan (eds.), Ritus infidelium, Madrid, Casa de Velázquez, 2013, pp. 133-149.

32 P. Alfonso, Diálogo..., p. 291.

33 Historia Arabum..., V, 84-94.

34 Ibíd., III, 12-14

35 O. R. Constable, "Regulating religious noise: the Council of Vienne, the mosque call and Muslim pilgrimage in the late medieval Mediterranean world", Medieval Encounters, vol. 16, núm. 1 (2010), pp. 64-95.

36 R. Salicrú, "Entre la praxis y el estereotipo: vivencias y percepciones de lo islámico ibérico en las fuentes archivísticas y narrativas bajomedievales", en J. Martínez Gázquez y J. V. Tolan (eds.), Ritus infidelium..., pp. 99-111. 
este pidió a sus seguidores que "siempre rezaran en dirección a aquella iglesia 37". Si bien, al parecer, muchos autores pensaban que esa dirección era el Sur y no el Este, por influencia, quizás, del hecho de que las mezquitas peninsulares estaban orientadas en esa dirección ${ }^{38}$. Hubo incluso algún autor cristiano que fue testigo directo de cómo los musulmanes rezaban, y así lo reflejó en su obra. Se trata del fraile dominico Riccoldo de Montecroce, quien viajó por Oriente Medio a finales del siglo XIII y vio en repetidas ocasiones cómo oraban sus compañeros de caravana ${ }^{39}$.

Pero, en todo caso, los polemistas cristianos normalmente trataron de ridiculizar este otro pilar del islam mediante dos estrategias. Por un lado, aseguraron que ese número de oraciones no fue más que un intento por parte de Mahoma de diferenciar su religión del judaísmo, que prescribe siete oraciones diarias, y del cristianismo, que prescribe tres ${ }^{40}$. Por otro, al vincularlo a las abluciones previas a la oración, se atribuía a los musulmanes la falsa creencia de que así se limpiaban los pecados, lo que a juicio de estos autores resultaba absurdo ${ }^{41}$. Algunos, como Pedro Alfonso, la consideraron una práctica sensual vinculada a un culto pagano a la diosa Venus ${ }^{42}$. Otros, como Montecroce, trataron, además, de ridiculizar la práctica permitida en el islam de realizar las abluciones con arena si no era posible encontrar agua, considerándola una forma sucia e irracional de purificación ${ }^{43}$.

El ayuno de Ramadán era también muy conocido entre los polemistas cristianos medievales, aunque ninguno quiso entender las razones de tal precepto, interpretándolo únicamente a la luz del ayuno cristiano ${ }^{44}$. Pedro Alfonso lo describe brevemente, pero mejor que cualquier otro autor, hasta el punto de que quizás su descripción fue producto de la experiencia, más que de cualquier tradición textual anterior ${ }^{45}$. También Jiménez de Rada lo menciona, solo que mucho más escuetamente que Alfonso; pero merece la pena ser destacado porque, hasta donde sabemos, es el único autor que además mencionó el ayuno de Muharram ${ }^{46}$. En cualquier caso, el ayuno de Ramadán fue el precepto islámico que más críticas recibió. Los autores cristianos lo consideraron una muestra evidente de hipocresía al permitir la ruptura del ayuno por las noches. Pensaban que esa ruptura era una excusa perfecta para darse a todo tipo de excesos. Ya Pedro Alfonso se preguntaba: "¿de qué aprovecha ayunar de día y, de noche, comer tres o cuatro veces y gozar de buenas carnes y de óptimos alimentos y frecuentar mujeres?"; y concluía afirmando que "esa costumbre no debilita la carne sino más bien la fortalece ${ }^{47 " . ~ Y ~ P e d r o ~ P a s c u a l, ~ p o r ~ s u ~ p a r t e, ~ c o n s i d e r a b a ~}$ que, con tal forma de ayunar, los musulmanes actuaban como si Dios no pudiera verles por la noche, lo que resultaba absurdo ${ }^{48}$.

37 Historia Arabum..., II, 47-48.

38 O. de la Cruz Palma, "Las cinco oraciones...".

39 Véase Ibíd; y, del mismo autor, Machometus: la invención del profeta Mahoma en las fuentes medievales, Bellaterra, Institut d'Estudis Medievals, 2017, p. 308.

40 P. Alfonso, Diálogo..., p. 299.

41 N. Daniel, Islam and the West..., pp. 235-236.

42 P. Alfonso, Diálogo..., p. 299.

43 R. Montecroce, Reprobación..., p. 18r.

44 N. Daniel, Islam and the West..., pp. 246-248.

45 P. Alfonso, Diálogo..., pp. 291-292

46 Historia Arabum..., III, 14-16.

47 P. Alfonso, Diálogo..., p. 299.

48 P. Pascual, Sobre la se[c]ta mahometana, edición y estudio de F. González Muñoz, Valencia, Universitat de València, 2011, p. 133. 
En cuanto a la peregrinación a La Meca, de nuevo fue Pedro Alfonso el autor que mejor la describió. No sólo mencionó el precepto, sino que describió también algunos de los ritos asociados a la peregrinación; en concreto la lapidación simbólica de Satanás ${ }^{49}$. Pero, obviamente, tampoco este era un precepto que se librara de su condena. Para él, los musulmanes no acudían a La Meca por devoción a Dios, sino siguiendo un antiguo ritual pagano que Mahoma no se había atrevido a eliminar. De hecho, únicamente había ocultado los ídolos anteriores. Alguno de ellos era el que estaba bajo la piedra que los peregrinos debían besar al rodear el santuario. Y, en cuanto a la lapidación de Satanás, señalaba su irracionalidad, "porque lo que no se percibe con ningún sentido corporal no puede ser puesto en fuga. Los demonios se ponen en fuga pronunciando el nombre divino ${ }^{50 "}$.

Muchos de los autores, sin embargo, interpretaron la peregrinación a La Meca en términos cristianos, como una forma de ganar la intercesión de Mahoma, pues pensaban que allí se encontraba su sepulcro, y que era esto lo que los peregrinos iban a visitar ${ }^{51}$. Acerca del supuesto sepulcro de Mahoma en La Meca correrá por Europa, hasta bien entrada la Edad Moderna, la leyenda de que estaba hecho de hierro y flotaba en el aire por efecto de unos imanes colocados estratégicamente en el mausoleo ${ }^{52}$. Y esto a pesar de que, al menos desde Lucas de Tuy (m. 1249), ya se sabía que, en realidad, su tumba se encontraba en Medina ${ }^{53}$.

Por último, la obligación coránica de dar limosna a los pobres es quizás el pilar del islam menos mencionado por los autores cristianos ${ }^{54}$. Ni siquiera Pedro Alfonso alude a él, y los autores que sí lo mencionan lo suelen hacer sólo de pasada. Rarísimos son los casos en los que se describe con algún detalle ${ }^{55}$. Uno de esos casos extraños es el de Riccoldo de Montecroce, quien, no, obviamente, en el contexto de su polémica contra el islam, sino en el del relato de su viaje por Oriente Medio, describió como algo encomiable la generosidad de los musulmanes a la hora de dar limosna ${ }^{56}$.

Hasta el final de la Edad Media, lo que la mayoría de los autores cristianos demuestra saber acerca de la religiosidad islámica no va mucho más allá ${ }^{57}$. A pesar de que su visión se enriquece con el conocimiento de las grandes recopilaciones de hadices, algunas crónicas históricas árabes y el famoso Libro de la escala, toda su preocupación está dirigida a demostrar la falsedad de la religión islámica, y especialmente a probar que Mahoma es un falso profeta. Poco les interesa saber cómo los musulmanes interpretan esos textos sagrados, y mucho menos cómo viven su religión día a día. Sobre un aspecto tan importante del islam como es la mística sufí parecen haber sabido más bien poco. Sí se sabía de la celebración de peregrinaciones a los mausoleos de los "santones" sufíes, ya que se daban incluso en territorios dominados por los cristianos, como muestra la carta puebla de Chivert (1234) y el hecho de que el mencionado Concilio de Vienne prohibiera ese tipo de

49 P. Alfonso, Diálogo..., p. 292.

50 Ibíd., p. 299-301.

51 Véase, por ejemplo, P. Pascual, Sobre la se[c]ta mahometana..., p. 159. Sobre este tema véase Daniel, Islam and the West..., pp. 243-246.

52 A. Eckhart, "Le cercueil flottant de Mahomet", en Mélanges de philologie romane et de littérature offerts à Ernest Hoepffener, París, Les Belles Lettres, 1949, pp. 77-88.

53 L. de Tuy, Crónica de España, edición de J. Puyol, Madrid, RABM, 1926, p. 206.

54 O. de la Cruz Palma, Machometus..., p. 320.

55 N. Daniel, Islam and the West..., pp. 248-250.

56 Cit. en O. de la Cruz Palma, Machometus..., p. 321.

57 N. Daniel, Islam and the West..., pp. 253-254. 
"romerías ${ }^{58 "}$. También parece que se conocía la existencia de cofradías sufíes: Ruy González de Clavijo, a principios del siglo XV, describe brevemente una de ellas, considerándola una orden de eremitas dirigida por un "mayoral" que era tenido por santo ${ }^{59}$. Pero el único autor, hasta donde sabemos, que describió un ritual sufí, fue Montecroce, aunque lo hizo sin darse cuenta de ello, pues más bien parece que lo consideró la forma normal de realizar la oración ${ }^{60}$. Así pues, en definitiva, poco cabe encontrar en la literatura medieval cristiana acerca de la religiosidad islámica, más allá, como decimos, de lo que los principales textos de la tradición islámica estipulan con claridad.

\section{LA ÉPOCA MODERNA}

La base del conocimiento que los europeos tenían del islam seguía siendo casi exclusivamente textual al comenzar el siglo XVI. De hecho, para la mayor parte de la producción intelectual europea dedicada al islam, seguiría siendo así durante varios siglos más. Esto es lo que llevó a Edward Said a considerar que una de las principales características del acercamiento europeo al islam era la adopción de una "actitud textual" que había dado forma a una tradición intelectual, a "un discurso" sobre el Oriente que tenía más peso en la forma en la que los europeos percibían el mundo islámico que la propia experiencia sobre el terreno ${ }^{61}$. Ciertamente, eso sería aplicable, en todo caso, a las obras de polémica, a los tratados de teología y filosofía, incluso a muchas obras de historia. Sin embargo, en paralelo a esta tradición surgió otra que planteaba un acercamiento diferente a lo islámico, un acercamiento que valoraba, por encima de todo, la experiencia, y que huía, en principio, de esa mencionada "actitud textual", haciendo depender la veracidad de la información que se transmitía de que tuviera como origen la observación directa. A esto Almut Höfert lo ha considerado el surgimiento de "un nuevo modelo epistemológico ${ }^{62 " . ~}$

Es en la literatura de viajes, heredera directa de las obras medievales del propio Montecroce, de Marco Polo o Jean de Mandeville, donde este cambio es más fácilmente detectable. Pero también en otro tipo de textos estrechamente vinculados a ese género: los diarios de embajadas, los relatos de cautivos o las obras de geografía. En estas obras la veracidad de la información no sólo se basa en la experiencia —que algunas veces es real y otras ficticia—, sino que, además, en ocasiones se afirma explícitamente en contra de la información cuyo origen no es empírico. Así, dice el autor del Viaje de Turquía, lo que más le animó a "pintar al bibo [...] el poder, vida, origen y costumbres de su enemigo [i.e. los turcos]", así como la vida de los cautivos en Constantinopla, fue ver cómo otros contaban esas cosas "no dando a su escriptura más autoridad del diz que, y que oyeron dezir a uno que venía de allá63". Él, sin embargo, lo que contaba lo había visto con sus propios ojos, lo había sufrido en sus carnes, y por eso era más digno de crédito.

Resulta paradójico que precisamente este texto que hace tanta gala del valor de la experiencia directa esté, casi todo él, basado en lo que otros textos dicen ${ }^{64}$. Pero, en

58 O. R. Constable, "Regulating religious noise...".

59 R. González de Clavijo, Embajada a Tamorlán, edición de F. López Estrada, Barcelona, Castalia, 2017, pp. 188-189.

60 Cit. en O. de la Cruz Palma, Machometus..., p. 308.

61 E. Said, Orientalismo, Barcelona, Debolsillo, 2003, pp. 84, 117-118, 122-123, 135-136.

62 A. Höfert, "The order of things and the discourse of the Turkish threat", en A. Höfert y A. Salvatore (eds.), Between Europe and Islam, Bruselas, PIE-Peter Lang, 2000, pp. 39-70.

63 Viaje de Turquía (la odisea de Pedro Urdemalas), edición a cargo de F. García Salinero, Madrid, Cátedra, 2010, pp. 88-89.

64 Sobre las fuentes usadas por el autor del Viaje véase la introducción de García Salinero en ibíd., pp. 36-42. 
cualquier caso, lo que cuenta es el principio: la autoridad de lo que otros han dicho ya no es suficiente para determinar la veracidad o no de una información, lo más importante es la experiencia en primera persona. La Topographía está llena de expresiones que transmiten al lector esa idea, que lo que se cuenta tiene como único origen la experiencia personal: "Preguntándoles yo la razón", "respondí yo a uno", "porque vimos con nuestros ojos", etcétera ${ }^{65}$. Es el principio de una actitud —-formulada, aunque no siempre practicada fielmente- que podríamos considerar científica en el sentido moderno.

La aparición de esta otra perspectiva, que se separa de manera decidida de la tradición polémica anterior, que en muchas ocasiones ni siquiera la cita, ni la utiliza, es lo que va a permitir la aparición de una serie de descripciones aparentemente verídicas de las formas en las que los musulmanes practican su religión en su vida diaria, más allá de lo que los textos sagrados o las obras de jurisprudencia puedan decir. Así, Diego de Haedo nos dice expresamente: "solamente apuntaré aquí parte de muchas opiniones, costumbres y usanzas que generalmente los más dellos usan, creen y observan, ultra de lo que Mahoma les manda66". Nótense las puntualizaciones, porque resultan muy interesantes. Haedo no sólo nos dice expresamente que nos hablará de las costumbres de los musulmanes que van más allá de las propias prescripciones coránicas, sino que, además, nos avisa de que esas costumbres no las siguen todos por igual, y que, por lo tanto, los musulmanes practican su religión de diversas formas. Refiriéndose al caso de la Argel de finales del XVI esto era especialmente pertinente, dada la gran variedad de orígenes etnoculturales de los musulmanes de la ciudad —que implicaba a veces adscripciones a diferentes escuelas de interpretación de la Ley (madahib, sing. madhab) - , algo que el mismo Haedo no deja de señalar ${ }^{67}$. Dentro de una tradición cristiana dedicada a describir la religión islámica como un monolito inamovible desde Mahoma, en la que se considera a los musulmanes indistinguibles unos de otros en cuanto a su religión, este tipo de puntualizaciones resultan sorprendentes y son una muestra de que, efectivamente, estamos ante un tipo de aproximación totalmente novedosa.

Esas descripciones, pues, ya no se realizan, como en la tradición polémica, exclusivamente para tratar de demostrar la falsedad del islam. Aunque las expresiones de condena y las caricaturizaciones todavía están presentes, las descripciones no se realizan con el objetivo de demostrar lo equivocados que están los musulmanes. Este es un punto de partida que nadie discute y que los autores no sienten la necesidad de demostrar. Es cierto también que en algunas de estas obras, especialmente en las relaciones de los cautivos, puede existir una motivación política: estimular una reacción por parte de la Monarquía que remedie la situación de los cautivos. En algunos casos se postula incluso una intervención $\operatorname{armada}^{68}$. Pero muchas de las descripciones de las prácticas religiosas islámicas denotan una genuina curiosidad, en una época en la que la mera curiosidad es el motor de infinidad de obras ${ }^{69}$. Así lo expresó claramente Ludovico de Varthema cuando describía la peregrinación a La Meca: "diré en aquesta parte lo más brevemente que yo pudiere la manera de sus sacrificios, para que pueda complir con los desseosos de saber novedades" ${ }^{\prime 70}$. Así pues, en

65 D. de Haedo, Topographía..., fols. 32v a, 33v b, 36v a.

66 Ibíd., fol. 32r a.

67 Ibíd., fols. 8r-9r.

68 M. Á. de Bunes ha defendido que existe en esta literatura una ideología "precolonial"; véase su La imagen de los musulmanes..., pp. X y 8.

69 Véase R. J. W. Evans y A. Marr (eds.), Curiosity and wonder from the Renaissance to the Enlightenment, Abingdon y Nueva York, Routledge, 2016.

70 L. de Varthema, Itinerario del venerable varón micer Luis patricio romano, Sevilla, Jacobo Cromberger, 
muchas ocasiones lo que lleva a estos autores a investigar y a describir las prácticas de los musulmanes es el mero deseo de conocer y transmitir conocimiento por el conocimiento mismo ${ }^{71}$.

Siendo la experiencia, entonces, el principio básico a partir del cual entender la religión islámica, son las prácticas, y no la teología, lo que estos autores van a describir. Los textos sagrados del islam, que desde el siglo XII habían ocupado el centro de la polémica, pasan a un segundo lugar en este tipo de obras, si es que ocupan verdaderamente algún lugar. Los cinco pilares del islam se mencionan, se explican, pero lo que atrae principalmente la atención de los autores no son los preceptos en sí, sino su práctica. Por otro lado, como decimos, la falsedad del islam es un punto de partida indiscutible que los autores no sienten necesidad de demostrar. Se enuncia en diversas ocasiones, pero los textos no se convierten en una refutación sistemática. De esta manera, a diferencia de lo que sucedía en la tradición medieval, la exposición de las creencias y prácticas del islam no va siempre acompañada de la refutación pertinente. Aunque algunos autores, como Diego de Haedo, no dejan de salpicar sus textos con condenas y burlas, otros, como el del Viaje de Turquía, hacen más bien lo contrario: muestran reconocimiento y admiración hacia la forma en la que los musulmanes viven su religión —esto seguramente explica por qué el primero pudo ver su libro publicado y el segundo no-.

\subsection{La profesión de fe}

Al ser, por tanto, la práctica, y no tanto la creencia o el principio teológico, lo que preocupa principalmente a estos autores, no es extraño que la profesión de fe islámica no se analice en sí misma, sino que se mencione especialmente en el contexto de la ceremonia de la conversión al islam, y que, por ello, se vincule también a la circuncisión.

Así, el autor de la Topographía se centra en las celebraciones que se realizan con motivo de la circuncisión: cómo se invita a una serie de conocidos a una gran fiesta, y después de la comida se procede a la circuncisión, realizada, según cuenta, casi siempre por "algún judío maestre deste oficio". Inmediatamente después de realizada, los asistentes comienzan a pronunciar la profesión de fe: "Yla Yla Ala Mahamet hera curra Ala, etcétera, que quiere dezir, Dios es y Dios será, y Mahamet es su mensagero". A esto sigue un gran alboroto del resto de asistentes, que hacen mucho ruido con el objetivo de distraer el pensamiento del circuncidado, el cual, poco después, se echa a descansar, "mientras los invitados a la fiesta le dan regalos". De especial interés para el autor es señalar que muchos cristianos cautivos en Argel se convierten al islam, y que esto es causa de gran alegría entre los musulmanes. A esos los genízaros, espada en mano y con su bandera, los pasean por la ciudad vestidos a la turca, "con una flecha en la mano", acompañados por un gran número de personas, "con música y lanzando vítores ${ }^{72 " . ~}$

Nótese que en ningún texto medieval dedicado al islam se hace nada semejante: conocen la circuncisión, saben incluso que se diferencia de la circuncisión judía en cuanto al momento de su realización, pero nada saben de cómo se realiza. Eso no les interesa, porque no ayuda en ninguna forma a los objetivos de la polémica religiosa. Ahora, los autores están movidos por un interés genuino en conocer formas de vida diferentes, y quieren saber cómo hacen las cosas. Por eso se detienen en este tipo de descripciones.

1520, fol. 10r b.

71 Sigo aquí a R. Irwin en For lust of knowing: the orientalists and their enemies, Londres, Penguin, 2007.

72 D. de Haedo, Topographía..., fol. 10r a-b. 
Sorprende igualmente que Haedo preste atención también a la ceremonia de conversión de las mujeres, y que mencione la cuestión de la ablación, que él Ilama "circuncisión". Sorprende este relato no sólo por la atención que presta a las costumbres femeninas una constante en toda la obra-, sino porque muestra que, como ya hemos apuntado, el autor es consciente de que no todos los musulmanes practican su religión de la misma manera, de que existen variantes de las mismas prácticas según la región o el grupo étnico, y que prácticas que en unos sitios son comunes, en otros sitios no lo son. Así, nos asegura que la conversión de las mujeres solo consiste en que se bañan, rezan, se les corta un poco el cabello, y adoptan un nombre árabe o turco ${ }^{73}$. Pero más abajo, basándose en una información transmitida por León el Africano ${ }^{74}$, nos dice que a la circuncisión sólo están obligados los hombres, "aunque en el gran Cayro y otras partes suelen también circuncidar a las hembras, cortándoles de sus miembros cierta carne superflua", pero esto, nos recalca, en Argel no se hace ${ }^{75}$.

\subsection{La oración}

Que el islam prescribía cinco oraciones diarias era sabido desde hacía mucho tiempo, como vimos. Pero a partir del siglo XVI no sólo se sabe eso, se sabe también cuándo exactamente tienen lugar esas oraciones y cómo se llaman. Los autores se recrean detallando el nombre exacto de cada oración —unos en árabe, otros en turco—, y situándolas en el tiempo ${ }^{76}$. Igual que los autores medievales, también prestan atención a la llamada del almuédano, señalando incluso qué dice exactamente ${ }^{77}$. Diego de Haedo da todavía más detalles acerca de cómo se hace la llamada, mostrando que seguía siendo una costumbre desagradable para los cristianos ${ }^{78}$.

Pero, aunque las cinco oraciones son de gran importancia, Diego de Haedo nos informa de que para los musulmanes "es de grande merecimiento hazer el salá [i.e., salah, la oración] quando les toca el coraçón y convida a hazerlo, y muy mayor que no a las horas acostumbradas y de obligación ${ }^{79 "}$. Estos autores tampoco se olvidan de las abluciones, pero ahora no dedican ningún improperio contra esa práctica, aunque el autor de Viaje de Turquía sigue pensando que son una forma de limpiar los pecados, un sustituto de la confesión cristiana ${ }^{80}$. Lo interesante es que se fijan en los detalles de cómo se realiza este acto. Así, el autor de la Topographía nos explica que los musulmanes de Argel consideran de más mérito realizar las abluciones con agua fría en lugar de con agua caliente ${ }^{81}$.

Pero lo más importante es cómo describen la realización de la propia oración. Aunque la descripción que cabe encontrar en la Topographía es menos prolija en detalles que la que se puede encontrar en, por ejemplo, el Viaje de Turquía ${ }^{82}$, destacando ante todo que se trata como de una "dança" dirigida por el imán, cuyos movimientos son imitados por los

73 Ibíd.

74 L. Africanus, Descripción general del África y de las cosas peregrinas que allí hay, traducción y edición de S. Fanjul, Barcelona, Lunwerg, 1995, pp. 153 y 323.

75 Ibíd., fol. 26v b.

76 Ibíd., fol. 21r b; Viaje de Turquía..., p. 389.

77 Ibíd.

78 D. de Haedo, Topographía..., fol. 21v a.

79 Ibíd., fol. 32r a.

80 Viaje de Turquía..., p. 388.

81 D. de Haedo, Topographía..., fol. 32r b.

82 Viaje de Turquía..., p. 390. 
fieles, colocados en hileras a lo largo de la mezquita ${ }^{83}$, recoge, en cambio, una información que es quizás la primera vez que un autor cristiano recoge: la oración puede invalidarse si se realiza en condiciones de impureza:

De la misma manera dicen que el salá no aprovecha si el que le haze, por desastre, dexa yr el viento por la parte no limpia. No se hable de la orina, porque dizen que no ay pecado ygual, como tocarles una gota della en los calçones, y por esso suelen mear siempre en cuclillas, como mugeres, y sería gran pecado mear en pies como christiano. [...] Tampoco le vale el salá si al que le haze le sale sangre de las narizes o de alguna llaga que tenga, aunque oculta $^{84}$.

También suelen estos autores hacer referencia a la oración del viernes, la más importante al tener lugar en el día santo del islam. Si los autores medievales habían hablado del viernes, lo habían hecho para apuntar su supuesta relación con Venus, la sensualidad y el paganismo. Ahora, en cambio, se fijan en que es un día especial porque los musulmanes están más obligados a ir a la mezquita a rezar; y a la mezquita mayor acuden las autoridades ${ }^{85}$. Haedo, además, hace referencia a las oraciones que tienen lugar en Ramadán, un momento especialmente importante para la religiosidad islámica. En esas fechas, nos dice, "los que son más debotos se lavan muy bien y van a las mezquitas hazer el salá y oyr la prédica y sermón ${ }^{86 " . ~}$

\subsection{El ayuno}

El ayuno de Ramadán también había recibido grandes críticas en la Edad Media, como vimos. Sin embargo, parece que este tipo de autores del siglo XVI no compartieron ese punto de vista. El autor de la Topographía ofrece descripciones muy detalladas y certeras acerca de en qué consiste el ayuno en sí —repitiendo grosso modo lo que ya Pedro Alfonso había señalado-, y añadiendo, además, muchos detalles que resultan de gran interés. Alguno de ellos parece exagerado, como su afirmación de que todos los musulmanes han de guardar el ayuno "so pena de ser quemados vivos"; y otros resultan más creíbles, como que los diferentes momentos para romper el ayuno están marcados públicamente mediante el uso de timbales que se tocan por toda la ciudad. También se señala que esa ruptura puede hacerse de una vez o en dos veces a lo largo de la noche; o que, mientras niños, y hasta mujeres preñadas, están obligados a hacerlo, los musulmanes recién convertidos al islam, como "no son tan legítimos moros", no lo observan en absoluto y siguen comiendo a placer, "pero retirados para que no los vean". Cuenta igualmente que algunos musulmanes llevan su devoción al extremo de no comer aunque estén de viaje, a pesar de que no están obligados. Otros, más extremos aún, no ayunan un mes, sino tres, algo que Haedo consideraba producto del engaño en el que los morabitos les tenían ${ }^{87}$.

EI Ramadán era -y es-especialmente propicio para el retiro espiritual y la predicación, lo cual es algo que Haedo también refleja, cuando dice que los sufíes se dedican en estas fechas a predicar "leyendo algún capítulo del Alcorán, haziendo algún discurso sobre él, exhortándolos al bien vivir, y muchos de ordinario tienen por uso de estar sentados en las

83 D. de Haedo, Topographía..., fols. 21r b-21v a.

84 Ibíd., fol. 32r b.

85 Ibíd., fol. 12v b, 14v b, 31v b-32r a.

86 Ibíd., fol. 30v a.

87 D. de Haedo, Topographía..., fols. 30r b-30v a. 
mezquitas con el Alchorán en la mano y quien quiere oyr algún capítulo se llega a ellos, y, acabado de leerle, da alguna limosna por el trabajo de la lición ${ }^{88 " . ~}$

También hace referencia Haedo a la Laylat al-Qadr o Noche del Destino, y describe las prácticas realizadas para celebrarla: se realiza una gran cena y se da limosna a los pobres, y algunos dejan comida "por todas partes y rincones de la casa para que vengan a comer los espíritus malos, diziendo que con esto los aplacan"89". Esa noche los musulmanes también encienden muchas lámparas en las mezquitas, y van de mezquita en mezquita por toda la ciudad, rezando. En los barcos también se encienden lámparas, y piensan que esa noche ocurre un prodigio: durante media hora las aguas no se mueven, y aquel que tiene la fortuna de encontrar las aguas dispuestas de esa manera obtendrá todo lo que desee de Dios $^{90}$.

Pero, sin duda, lo más interesante es la atención que presta Haedo a las celebraciones que tienen lugar a lo largo del mes sagrado, en primer lugar a una que recuerda en parte a una fiesta carnavalesca:

Se juntan una noche [de Ramadán] como treynta o quarenta y más hombres y son todos turcos o renegados, y hazen con ciertos palos que arman y atan un cuerpo de camello con su corcoba y puesta una cabeça [...], y llevando delante una gayta tañendo van todos baylando con sus máscaras, y llegando a las puertas de los más ricos y principales tanto tocan que los abren y les dan estrenas de dineros, como quiere cada uno, una dobla, dos o tres, y más, lo qual todo reparten después entre sí ygualmente ${ }^{91}$.

También ofrece Haedo una descripción muy interesante de las celebraciones que tienen lugar con motivo del Eid al-Fitr, la fiesta de la ruptura del ayuno ${ }^{92}$. Ese día, nos cuenta, salen todos los musulmanes de la ciudad al campo, donde hacen una oración conjunta a la que asiste el gobernador de la ciudad, a la que sigue un sermón del "morabuto mayor", quien les exhorta a dar gracias a Dios y a observar las prescripciones coránicas, y les promete la salvación. Después, una vez vueltos a sus casas, hacen grandes banquetes y diversos juegos públicos. Los jóvenes "cavalgan en cavallos y se visten lo mejor que pueden y salen fuera de la puerta de Babaluete, y en la playa escaramuçan con cañas, y después corren sus carreras de dos en dos". Por su parte, el común del pueblo se junta para hacer bailes semejantes, nos dice, a los que hacen los negros de Guinea en Sevilla y Lisboa. En esos bailes se separan según procedencias: Ios moros del Sáhara por un lado, los de la Kabilia por otro, los negros por otro, y las negras por otro; "y cada nación bayla y toca sus tabales o gaytas a la usança de su tierra". Los árabes, en cambio, no participan en esos bailes, dado que, nos dice Haedo, "son en todo villísima gente y para poco". Tampoco los turcos lo hacen, ni los conversos, porque consideran que no es digno de ellos. En cambio, los turcos sí hacen combates de lucha libre. Otros se montan en una especie de atracciones que se erigen en la ciudad: unos columpios que se hacen con "ciertas horcas de tres palos muy altos y muy fixos, y en unas sogas que cuelgan dellos muy largas, en las puntas de las quales atan unas tablas sobre las quales se assienta el que se quiere columpear o mecer". Otros, en cambio, se dedican a un juego que resulta difícil de identificar:

88 Ibíd., fol. 21v a.

89 Ibíd., fol. 30v b.

90 Ibíd., fols. 31r a-31r b.

91 Ibíd., fols. 30v a-30v b.

92 Véase todo lo que sigue acerca del Eid al-Fitr en Ibíd., fols. 30v b-31r a. 
Hazen unos instrumentos redondos de palo, como los tornos con que en Christiandad alçan y dan cal y ladrillo y otras cosas necessarias a los que trabajan en alguna torre o pared alta, a que en español llaman polea o cabrilla o argana, y cavalgando uno en cada punta de los palos que atraviessan aquel instrumento, los hazen boltear alrededor, y de arriva abaxo; y, acabado, paga cada uno un áspero para el que plantó estos palos y hizo este juego, y con esto, sin más juegos ni fiestas, celebran su pascua ${ }^{93}$.

En estas celebraciones también participan los cristianos cautivos, "por ganar algunas blancas", lo cual Haedo condena, porque, según él, Dios no los llevó a Argel a festejar, sino para sufrir y aplacar así la ira divina. Estos se ponen máscaras y hacen danzas como suelen hacer los cristianos. Hacen también concursos de puntería con arcos y flechas, y títeres, y también juegan al "passa passa con algunas destrezas de manos." No se trata de actividades festivas realizadas por separado, sino que todas las comunidades participan. Así, Haedo nos dice que a esos juegos de los cristianos asisten moros y turcos, que se "huelgan mucho y lo miran como abobados $94 "$.

\subsection{La peregrinación}

La peregrinación anual a La Meca fue, como vimos, uno de los pilares mejor conocidos en la Cristiandad medieval. Sin embargo, la mayoría de los autores mantenía una idea equivocada del precepto coránico. En la Topographía, sin embargo, no cabe encontrar ninguna descripción de este pilar, dado que el autor nunca estuvo en La Meca y el objetivo de toda la obra es contar lo que él sabía por su propia experiencia o por lo que le habían contado testigos directos de los hechos. Por ello, nada se dice de la peregrinación en sí, e incluso sigue afirmando que su objetivo es la visita de la tumba de Mahoma, lo que muestra que resultaba difícil sustraerse al peso de la tradición - aunque es cierto que aclara que no está enterrado "en arca de azero como algunos christianos vulgarmente afirman"5"-

En cambio, sí se incluye información acerca de lo que hacían algunos peregrinos al volver, y cómo eran tratados por el resto de habitantes de la ciudad. Según cuenta Haedo, los musulmanes de Argel sentían gran veneración por los que volvían de La Meca. Los trataban como morabitos o santos y corrían a besarles las manos y la ropa. Además, les llamaban "Agi, que quiere dezir peregrino ${ }^{96 " . ~ Y, ~ n o s ~ c u e n t a, ~ m u c h o s ~ d e ~ l o s ~ p e r e g r i n o s ~ s o l i ́ a n, ~}$ "después que han visto el sepulcro de Mahoma, quitarse un ojo de su propia voluntad, y aún algunos ambos los ojos, diziendo que quien tal a visto no cumple que mire más otra cosa, y que ojos tan dichosos y que tal miraron no conviene que sirvan para mirar otras cosas ${ }^{97 "}$.

Pero es sin duda la descripción que hace Haedo del ritual del sacrificio durante el Eid al-Kabir lo que resulta más interesante, pues, aunque es un rito vinculado a la peregrinación, se realiza en todo el mundo islámico y no sólo en La Meca, por lo que él mismo —o quien escribiera la obra - pudo presenciar cómo se realizaba. Durante esta celebración, nos dice, los habitantes de Argel hacen los mismos juegos que se hicieron en durante la fiesta de la ruptura del ayuno, pero, además, "en memoria del sacrificio que hizo el Patriarca Abraham", cada padre de familia está obligado a sacrificar un carnero, "y otros que son ricos matan algunas vezes tantos quantas personas ay en la familia". El sacrificio se realiza de esta manera:

93 Ibíd., fol. 31r a.

94 Ibíd.

95 Ibíd., fol. 32v a.

96 Ibíd.

97 Ibíd., fol. 32v b. Puede que aquí se refiriera a alguna de las prácticas de automutilación que efectuaban los miembros de algunas cofradías sufíes, pero es difícil saberlo con seguridad. 
Vienen de hazer el salá en el campo, fuera de la ciudad (do se juntan todos con el rey, [...]) y estando ya aparejados los carneros en casa, cada qual toma el suyo, y buelto al mediodía, primeramente laban la cara y hocico del carnero con agua y le sahuman con incienso o algún buen olor y luego le degüella él mismo con su mano, aunque sea el mismo rey, porque en esto ponen todo el mérito, y aquella sangre las mugeres la coxen y guardan [...] diziendo que es santa y bendita de Dios y buena para mal de ojos. Y algunos tienen por devoción teñir la frente con esta misma sangre rezién salida. [...] Hecha esta ceremonia, y desollado el carnero, luego le pintan assí entero con azafrán y le dexan estar colgado hasta el día tercero, y después, dando a los pobres una parte, no grande, se come en casa lo demás o lo guardan salado y curado al sol, como una cosa bendita y santa ${ }^{98}$.

Haedo no realiza mayor comentario; toda la descripción se realiza con una aparente objetividad. Nótese que Haedo afirma que el sacrificio se realiza mirando hacia el Sur y no hacia Oriente, lo que puede ser consecuencia de la diferencia de orientación de las mezquitas en el Magreb. Por otro lado, véase también la puntualización acerca de que la parte que se da a los pobres es pequeña. Esto está en línea con la tendencia general del autor a criticar la falta de generosidad de los musulmanes y su escasa caridad, como veremos a continuación.

\subsection{La limosna}

Los autores cristianos medievales prestaron muy poca atención al precepto coránico de la limosna. Únicamente Montecroce realizó una descripción de él con algún detalle. En la Edad Moderna sigue siendo una de las cuestiones menos tratadas, pero, aún así, se trata más que en la Edad Media. Haedo habla del asunto, pero la falta de generosidad que atribuye a los musulmanes argelinos parece exagerada. De hecho, es tan extrema que llega a decir que en pleno invierno de 1579, en medio de una hambruna, cuando los pobres se agolpaban en las calles de la ciudad bajo la lluvia, muriendo de hambre, nadie se preocupó de socorrerlos, y que, incluso, "un turco arto rico", en lugar de ayudar a uno que pedía pan, lo ahogó haciéndole beber agua de un canalón ${ }^{99}$. Y es que, según Haedo, los moros y los turcos son las personas más avarientas del mundo ${ }^{100}$, por lo que nunca dan limosna. Sólo las mujeres, "como más tiernas naturalmente, dan algunos pedaços de pan a los pobres"; pero ellos, en cambio, "a cozes y a bofetones los echan y apartan de sí". Más aún: los argelinos tampoco cuidan a los huérfanos, ni casan a las huérfanas o a las viudas, ni hacen las "obras todas de piedad y que tanto usan los cristianos ${ }^{101 " . ~ Y ~ t o d o ~ e l l o ~ l o ~ a f i r m a ~}$ a pesar de que reconoce que los musulmanes están obligados a dar "un dos y medio por ciento de todo lo que posseen", el llamado "assor" [i.e. ushr], a los pobres. Sin embargo, sostiene que con el tiempo ese porcentaje se ha reducido, pues sólo se extrae de lo ganado durante el año ${ }^{102}$.

En realidad parece que la caracterización que hace de los musulmanes en este punto está bastante viciada por los prejuicios. No es sólo que caiga en exageraciones como la mencionada, sino que, además, de hecho, contradice lo que él mismo señala en otras partes de la obra, donde hace referencias a las muestras de caridad de los musulmanes. Por ejemplo, menciona que algunos morabitos "viven de limosnas que vienen a pedir a la

98 Ibíd., fols. 31r b-31v a.

99 Ibíd., fols. 37r b-37v a.

100 Ibíd., fol. 37r a.

101 Ibíd., fol. 37r b-37v a.

102 Ibíd., fol. 37r b. 
ciudad", de modo alguno debían recibir. De igual manera cuenta que algunos morabitos acarreaban agua en verano y la repartían a moros, turcos o cristianos, y esto por pura devoción, "por amor de Dios ${ }^{103 " . ~ A s i m i s m o, ~ e n ~ s u s ~ v i s i t a s ~ a ~ l a s ~ t u m b a s ~ d e ~ l o s ~ m o r a b i t o s, ~ l o s ~}$ musulmanes solían dejar comida para los pobres que acudían allí104. Y, como vimos, en la Laylat al-Qadr también se repartía limosna entre los pobres ${ }^{105}$. Así que, después de todo, quizás no fueran tan avarientos y poco caritativos los argelinos.

\section{CONCLUSIÓN}

Es difícil que una sociedad genere las condiciones ideales para que surja dentro de ella quien sea capaz de describirla con imparcialidad, más aún cuando estamos hablando de uno de sus aspectos más delicados: la religión. Tampoco es fácil que del seno de una sociedad surja quien, despojado de prejuicios, pueda describir con justicia las formas de vida de otras sociedades, y menos de un aspecto tan delicado como la religiosidad de sus habitantes, más aún cuando esa religión ha sido tradicionalmente representada como una amenaza vital. Si tanto los testimonios internos como los externos están viciados por diferentes formas de tendenciosidad, ¿cómo podemos llegar a conocer la religiosidad de una sociedad en el pasado? La única forma, evidentemente, es reuniendo la mayor cantidad de información posible y contrastarla. Pero en este asunto que hemos tratado, tradicionalmente siempre se ha dado prioridad a los testimonios internos a la sociedad —en nuestro caso, testimonios islámicos para describir el islam—, olvidando quizás la problemática a la que nos hemos referido y la necesidad de recurrir a testimonios externos a la propia sociedad islámica.

Es cierto que, como apuntamos al comienzo, entre los textos europeos medievales es difícil encontrar nada que merezca ser tenido en cuenta como un testimonio fiel de la forma en la que los musulmanes vivían su religión. Existen algunas excepciones, como ciertos pasajes del Diálogo de Pedro Alfonso o del Itinerario de Riccoldo de Montecroce, pero siguen siendo demasiado pobres comparados con lo que puede encontrarse en las fuentes islámicas mismas. Sin embargo, en la Edad Moderna la situación cambia de forma sensible gracias al surgimiento, como dijimos, de un tipo de literatura que se aleja de la tradición polémica medieval y que valora ante todo la observación directa como fuente de información. Gracias a esto nos encontramos con testimonios que deben ser tenidos muy en cuenta en cualquier análisis de la religiosidad islámica entre los siglos XVI y XVIII.

En este sentido, el caso de la Topographía es especialmente importante, pues se trata de un testimonio, a nuestro juicio único, de las formas de vida de la Argel de finales del siglo XVI, especialmente de la religiosidad de sus habitantes. En nuestro caso nos hemos limitado a exponer lo que tiene que ver con los cinco pilares del islam, pero en esta fuente es posible encontrar muchísima información más acerca de aspectos tan importantes como las supersticiones, los amuletos, los ritos funerarios, algunas prácticas interreligiosas, y, sobre todo, acerca del sufismo y el culto a los místicos sufíes difuntos. Pero sólo limitándonos al caso de los cinco pilares hemos visto que la información que se puede obtener es muy rica y que las descripciones no parecen —en principio y mientras no puedan ser contrastadas con otras fuentes - distorsionadas, salvo por algunas exageraciones que hemos señalado.

Las descripciones de la ceremonia de conversión, tanto masculina como femenina no tienen precedentes en la literatura medieval. Ya a principios del siglo XVI, en las obras sobre las que se basa el Viaje de Turquía, era posible encontrar descripciones semejantes,

103 Ibíd., fol. 22r b.

104 Ibíd., fol. 29r a.

105 Ibíd., fol. 32v b. 
pero se centran en el contexto de Constantinopla. La única de este tipo referente al Magreb es, hasta donde sabemos, la de Haedo, lo que evidencia su valor. Ello, unido a las puntualizaciones acerca de las diferencias existentes entre las sociedades islámicas con respecto a un tema tan delicado como la ablación, hace de esta obra una fuente de información muy importante ${ }^{106}$.

Por otro lado, la sensibilidad que el autor demuestra a la hora de realizar observaciones como la del mérito que conceden los musulmanes a la oración fuera de las cinco estipuladas, o acerca de qué factores pueden hacer inválida una oración; o acerca de la importancia de la espiritualidad en Ramadán, o sobre las creencias vinculadas a la Laylat al-Qadr; da cuenta de hasta qué punto resulta ser un observador fiel a su experiencia y digno de crédito, al menos mientras no dispongamos de testimonios discordantes.

Finalmente, son de destacar las descripciones de las celebraciones del mes de Ramadán, así como las del Eid al-Fitr y el Eid al-Kabir. En la primera se encuentra un testimonio único de un tipo de celebración carnavalesca que recuerda a otras como el Nawruz de El Cairo medieval estudiado por Shoshan, en el que también había máscaras y grandes animales hechos con madera, en este caso elefantes ${ }^{107}$; o a los festivales carnavalescos que se celebraban unos días después del Eid al-Kabir -y no en Ramadán, como en el caso argelino- en zonas beréberes de Marruecos, Argel y Túnez entre los siglos XVIII y XX, y que han sido estudiados por Abdallah Hammoudi ${ }^{108}$. La Topographía ofrece en este punto el que quizás es el único testimonio existente de la celebración de este tipo de mascaradas en la Argel de finales del siglo XVI, lo que por sí sólo demuestra el valor del texto como fuente para el estudio de la religiosidad islámica altomoderna.

En definitiva, es posible que no exista una fuente de información sobre la religiosidad islámica magrebí de finales del siglo XVI que pueda ser comparada a la Topographía, a pesar de ser una fuente cristiana y a pesar de la tendenciosidad evidente de muchos de sus juicios y observaciones. Muestra, por ello, que las fuentes cristianas deben ser incorporadas en cualquier reconstrucción histórica de la religiosidad islámica, al menos a partir del siglo XVI.

\section{BIBLIOGRAFÍA}

Africanus, L., Descripción general del África y de las cosas peregrinas que allí hay, traducción y edición de S. Fanjul, Barcelona, Lunwerg, 1995.

Alfonso, P., Diálogo contra los judíos, traducción de E. Ducay, Zaragoza, Instituto de Estudios Altoaragoneses, 1996.

Berkey, J. P., The formation of islam: religion and society in the Near East, 600-1800, Cambridge, Cambridge University Press, 2003.

Berque, J., Al-Yousi: problémes de la culture marocaine au XVIlème siècle, Paris, Moutin \& Co., 1958.

Bunes Ibarra, M. Á. de, La imagen de los musulmanes y del norte de África en la España de los siglos XVI y XVII: los caracteres de una hostilidad, Madrid, CSIC, 1989.

Camamis, G., Estudios sobre el cautiverio en el Siglo de Oro, Madrid, Gredos, 1977.

Cardaillac, L., Moriscos y cristianos: un enfrentamiento polémico (1442-1560), 2a ed., Madrid, Fondo de Cultura Económica, 2016.

106 León el Africano recoge una pequeña descripción de la ceremonia y el festejo de la circuncisión, pero no en referencia a la conversión, sino en relación a la realizada siete días después del nacimiento del niño varón. En cuanto a la ablación, como apuntamos más arriba, realiza también la puntualización de que se trata de una práctica que sólo se observa en Siria y Egipto; véase nota 74.

107 B. Shoshan, Popular culture, pp. 40-51.

108 A. Hammoudi, The victim and its masks: an essay on sacrifice and masquerade in the Maghreb, Chicago, Chicago University Press, 1993. 
Constable, O. R., "Regulating religious noise: the Council of Vienne, the mosque call and Muslim pilgrimage in the late medieval Mediterranean world", Medieval Encounters, vol. 16, núm. 1 (2010), pp. 64-95.

Cruz Hernández, M., El islam de al-Andalus: historia y estructura de su realidad social, $2^{\mathrm{a}}$ ed., Madrid, AECl, 1996.

Cruz Palma, Ó. de la, "Las cinco oraciones islámicas diarias (Salawat) en las fuentes latinas medievales", en Martínez Gázquez, J. y Tolan, J. V. (eds.), Ritus infidelium. Miradas interconfesionales sobre las prácticas religiosas en la Edad Media, Madrid, Casa de Velázquez, 2013, pp. 133-149.

- Machometus: la invención del profeta Mahoma en las fuentes medievales, Bellaterra, Institut d'Estudis Medievals, 2017.

Daniel, N., Islam and the West: the making of an image, Oxford, Oneworld Pub., 1993.

Eckhart, A., "Le cercueil flottant de Mahomet", en Mélanges de philologie romane et de littérature offerts à Ernest Hoepffener, París, Les Belles Lettres, 1949, pp. 77-88.

Eisenberg, D., "Cervantes, autor de la Topografía e historia general de Argel publicada por Diego de Haedo", Cervantes: Bulletin of the Cervantes Society of America, vol. 16, núm. 1 (1996), pp. 32-53.

Evans, R. J. W. y Marr, A. (eds.), Curiosity and wonder from the Renaissance to the Enlightenment, Abingdon y Nueva York, Routledge, 2016.

Fierro, M., "Prácticas y creencias religiosas en al-Andalus", Al-Qantara, vol. 13, núm. 2 (1992), pp. 463-474.

Garcés, M. A., Cervantes en Argel: historia de un cautivo, Madrid, Gredos, 2005.

- "Introduction", en Sosa, A. de, An early modern dialogue with Islam: Antonio de Sosa's Topography of Algiers (1612), Notre Dame, Ind., University of Notre Dame Press, 2011, pp. 1-78.

García-Arenal, M., Inquisición y moriscos: los procesos del Tribunal de Cuenca, $3^{a}$ ed., Madrid, Siglo XXI, 1987.

García Sanjuán, A., "La celebración de la navidad en al-Andalus y la convivencia entre cristianos y musulmanes", en Miura, J. M. (ed.), Te cuento la navidad: visiones y miradas sobre las fiestas de invierno, Sevilla, Aconcagua, 2011, pp. 43-49.

Gonzalbes, C., "Un ensayo para la catalogación de los amuletos de plomo andalusíes", Boletín Arqueológico Medieval, 12 (2005), pp. 7-17.

González de Clavijo, R., Embajada a Tamorlán, edición de F. López Estrada, Barcelona, Castalia, 2017, pp. 188-189.

Halevi, L., Muhammad's grave: death rites and the making of Islamic society, Nueva York, Columbia University Press, 2007.

Hammoudi, A., The victim and its masks: an essay on sacrifice and masquerade in the Maghreb, Chicago, Chicago University Press, 1993.

Höfert, A., "The order of things and the discourse of the Turkish threat: the conceptualisation of Islam in the rise of Occidental anthropology in the fifteenth and sixteenth centuries", en Höfert, A. y Salvatore, A. (eds.), Between Europe and Islam: shaping modernity in a transcultural space, Bruselas, PIE-Peter Lang, 2000, pp. 39-70.

Ibn Battuta, A través del islam, traducción, introducción y notas de S. Fanjul y F. Arbós, Madrid, Alianza Ed., 2005.

Ibn Yubayr, A través del oriente (Rihla), estudio, traducción, notas e índices de F. Maíllo, Madrid, Alianza Ed., 2007.

Irwin, R., For lust of knowing: the orientalists and their enemies, Londres y Nueva York, Penguin, 2007. 
Jiménez de Rada, R., Historiae minores. Dialogvs libri vite, edición y estudio de J. Fernández Valverde y J. A. Estévez Sola, Turnhout, Brepols, 1999.

Kaptein, N. J. G., Muhammad's birthday festival: early history in the central Muslim lands and development in the Muslim west until the 10th/16th century, Leiden, Nueva York y Colonia, Brill, 1993.

Maliki, S., "Religiosidad y alteridad: una aproximación a la imagen del musulmán en la Topografía e Historia general de Argel de Antonio de Sosa”, 'Ossour al-Jadida, 19-20 (2015), pp. 66-82.

Montecroce, R., Reprobación del Alcorán, Sevilla, por dos alemanes compañeros, 1501.

Parreño, J. M., "Experiencia y literatura en la obra de Antonio de Sosa", en Sosa, A. de, Diálogo de los mártires de Argel, Madrid, Hiperión, 1990, pp. 9-23.

Pascual, P., Sobre la se[c]ta mahometana, edición y estudio de F. González Muñoz, Valencia, Publicacions de la Universitat de València, 2011.

Rodríguez Mediano, F., "Santos arrebatados: algunos ejemplos de maydub en la Salwat alanfas de Muhammad al-Kattani”, Al-Qantara, vol. 13, núm. (1992), pp. 237-256.

- "Religiosidad en al-Andalus: el hombre santo en el islam occidental", Revista de Dialectología y Tradiciones Populares, 54 (1999), pp. 145-168.

Sahin, K., "Staging an Empire: an Ottoman circumcision ceremony as cultural performance", American Historical Review, vol. 123, núm. 2 (2018), pp. 463-492.

Said, E. W., Orientalismo, $2^{\mathrm{a}}$ ed., Barcelona, Debolsillo, 2003.

Salah, M. M., El doctor Sosa y la Topografía e historia general de Argel, tesis doctoral, Departamento de Filología Española, Universidad Autónoma de Barcelona, Barcelona, 1991.

Salicrú, R., "Entre la praxis y el estereotipo: vivencias y percepciones de lo islámico ibérico en las fuentes archivísticas y narrativas bajomedievales", en Martínez Gázquez, J. y Tolan, J. V. (eds.), Ritus infidelium. Miradas interconfesionales sobre las prácticas religiosas en la Edad Media, Madrid, Casa de Velázquez, 2013, pp. 99-111.

Shoshan, B., Popular culture in medieval Cairo, Cambridge, Cambridge University Press, 1993.

Sola, E., "Renacimiento, Contrarreforma y problema morisco en la obra de Antonio de Sosa", en Sosa, A. de, Diálogo de los mártires de Argel, Madrid, Hiperión, 1990, pp. 27-52.

- "Antonio de Sosa: un clásico inédito amigo de Cervantes (Historia y Literatura)", en Actas del I Coloquio Internacional de la Asociación de Cervantistas, Barcelona, Anthropos, 1990, pp. 409-412.

Southern, R. W., Western views of Islam in the Middle Ages, Cambridge, Mass., Harvard University Press, 1962.

Tolan, J. V., Saracens: Islam in the medieval European imagination, Nueva York, Columbia University Press, 2002.

Tóth, J., "Topography of a society: Muslims, dwellers, and customs of Algiers in Antonio de Sosa's Topographia, e Historia general de Argel", en Birnbaum, M. D. y Sebok, M. (eds.), Practices of coexistence: constructions of the other in early modern perceptions, Budapest, Central European University Press, 2017, pp. 103-142.

Touati, H., Entre Dieu et les hommes: lettrés, saints et sorciers au Maghreb (17 $7^{e}$ siècle), París, École des Hautes Études en Sciences Sociales, 1994.

Tuy, L. de, Crónica de España, edición de J. Puyol, Madrid, Tip. de la RABM, 1926.

Varthema, L., Itinerario del venerable varon micer Luis patricio romano en el qual cuenta mucha parte de la Ethiopia, Egipto, y entrambas Arabias, Siria y la India, Sevilla, Jacobo Cromberger, 1520.

Viaje de Turquía (la odisea de Pedro Urdemalas), 6ª ed., a cargo de F. García Salinero, Madrid, Cátedra, 2010. 
Waardenburg, J. J., "Official and popular religion in Islam", Social Compass, vol. 25, núms. 3-4 (1978), pp. 315-341.

Wiegers, G., "Ibadat", en Martin, R. C. (ed.), Encyclopedia of Islam and the Muslim world, 2 vols., Nueva York, Macmillan Reference USA, Thomson/Gale, 2004, vol. 1, pp. 327333.

Zaragoza, E., "Abadologio del monasterio de Ntra. Sra. de la Misericordia de Frómista (1437-1835)", Publicaciones de la Institución Tello Téllez de Meneses, 71 (2000), pp. 135-158. 